\title{
Issues in Diagnosis and Treatment of Type 1 Diabetes Mellitus in Childhood
}

\author{
Laura Lucaccioni, Lorenzo Iughetti* \\ Post-Graduate School of Paediatrics, Departments of Medical and Surgical Sciences of Mothers, \\ Children and Adults, University of Modena \& Reggio Emilia, Paediatric Unit, Modena, Italy \\ Email: "lorenzo.iughetti@unimore.it
}

Received 22 February 2016; accepted 15 May 2016; published 18 May 2016

Copyright $@ 2016$ by authors and Scientific Research Publishing Inc.

This work is licensed under the Creative Commons Attribution International License (CC BY). http://creativecommons.org/licenses/by/4.0/

(c) (i) Open Access

\begin{abstract}
Type 1 Diabetes Mellitus remains one of the most complex chronic diseases in childhood. Although advances in knowledge and technology, as the use of insulin pumps or glucose sensors, have improved the quality of life of patients, the onset of the disease, as well as long-term treatment and diet, are pitfalls for families and clinicians. It is important to bear in mind that acute, life- threatening consequences of uncontrolled diabetes are hyperglycemia with ketoacidosis, both in new diagnosis and in patients already on treatment, and may be hidden by other symptoms. Moreover, treatment with insulin and diet should always be tailored on lifestyle habits and age of the patient. Aim of this work is to briefly summarise and comment what are the worst insidious aspects of Diabetes and what are the best strategies to improve the management of the disease in childhood.
\end{abstract}

\section{Keywords}

Type 1 Diabetes Mellitus, Hyperglycemia, Insulin Treatment, Autoimmunity, Diet

\section{Introduction}

Type 1 Diabetes Mellitus (T1DM) is a chronic condition characterized by persistent hyperglycaemia due to absolute or relative insulin deficiency. According to the recent classification published by the American Diabetes Association in January of 2007, T1DM can be classified into two subgroups: Immune mediated and Idiopathic [1].

The natural history of T1DM is characterized by the intersection of multiple risk factors as genetic predisposition and environment. A recent meta-analysis provided evidences that more than 40 distinct genomic locations were associated with T1DM. In particular, HLA genes present the strongest known association and a linkage to

${ }^{*}$ Corresponding author. 
specific combinations of alleles at the DRB1, DQA1 and DQB1 loci does exist, with both susceptible and protective haplotypes [2] [3]. However, the main known cause of T1DM is the progressive T-cell mediated autoimmune destruction of $\beta$ cells of the pancreas, manifested by low or undetectable plasma levels of C-peptide. Serological markers of autoimmune pathologic processes (islet cell, GAD, IA-2, IA-2 $\beta$, or insulin autoantibodies) are present in $85 \%-90 \%$ of children when fasting hyperglycemia is detected [4] [5]. The environmental triggers (chemical and/or viral) responsible of the onset of pancreatic beta cell destruction remain largely unknown, but the process usually begins months to years before the manifestation of clinical symptoms [6] [7]. Enterovirus is considered one of the most involved pathogens, due to its detection in the islets of individuals with diabetes; such viral infection has been associated with development of immune mediated diabetes [8]-[10]. The incidence of T1DM varies largely between countries, within countries and between different ethnic populations. A seasonal variation in new onsets is also well documented, with a peak during winter [11]. The real incidence in developing countries is still unknown [12], although the incidence of the disease is worldwide increasing [13].

\section{T1DM Diagnosis: Difficulties in Symptoms Interpretation}

Diagnostic criteria for T1DM are the same for children, young people and adults and are characterized by fasting glycemia $>126 \mathrm{mg} / \mathrm{dl}(>7.0 \mathrm{mmol} / \mathrm{L})$ or postprandial glycemia $>200 \mathrm{mg} / \mathrm{dl}(>11.1 \mathrm{mmol} / \mathrm{L})[1]$.

Symptoms of marked hyperglycemia are: polyuria, polydipsia, weight loss and sometimes polyphagia and blurred vision. Impairment of growth and susceptibility to infections may also be associated with chronic hyperglycemia. Clinical presentation of diabetes varies from non-emergency presentations to severe dehydration, shock and diabetic ketoacidosis. Acute, life-threatening consequences of uncontrolled diabetes are hyperglycemia with ketoacidosis or the non-ketotic hyperosmolar syndrome [13]-[15].

T1DM onset is hard to be diagnosed: most of the symptoms are difficult to be recognized because subjects are usually healthy children with no previous problems. Some children may have a rapid onset of symptoms and present within days with diabetic ketoacidosis (see below); others may have a slow onset over several months. Main T1DM symptoms could be confused as follow:

- The recent onset of enuresis in a previously toilet-trained child may be misdiagnosed as a urinary tract infection or the result of excessive fluid ingestion;

- Polydipsia may be thought to be psychogenic or simply related to weather conditions, especially in summer;

- Vaginal candidiasis, especially in prepubertal girls, could be thought as a low urinary tract infection or as an immune-suppression;

- Vomiting may be misdiagnosed as gastroenteritis;

- Chronic weight loss or failure to gain weight in a growing child could lead to bowel and/or feeding problems;

- Abdominal pain associated with ketoacidosis may simulate an acute abdomen and lead to referral to surgeons;

- Hyperventilation of ketoacidosis may be misdiagnosed as pneumonia or asthma (cough and breathlessness distinguish these conditions from diabetic ketoacidosis).

Urinary "dipstick" testing for glycosuria and ketonuria provides a simple and sensitive tool for excluding diabetes with less typical presentation. A blood glucose measurement (plasma glucose $>11.1 \mathrm{mmol} / \mathrm{L}$ ) rapidly confirms the diagnosis [13].

\section{Diabetic Ketoacidosis (DKA): Difficulties in Management}

The pathogenesis of DKA is summarized in Figure 1 [16].

If the process described in Figure 1 is not interrupted with exogenous insulin, fluids and electrolyte therapy, fatal dehydration and metabolic acidosis will ensue. Diabetic ketoacidosis may present in different ways with: severe dehydration, frequent vomiting with nausea and abdominal pain, continuing polyuria despite the presence of dehydration, weight loss due to fluid loss, muscle and fat impairment, flushed cheeks due to ketoacidosis, acetone detected on breath, hyperventilation (Kussmaul respiration characterized by a high respiratory rate and large tidal volume of each breath), progressive loss of consciousness (disoriented, semi-comatose or rarely comatose), shock (rapid pulse rate, poor peripheral circulation with peripheral cyanosis), hypotension (a late sign and rare in children with diabetic ketoacidosis), increased leukocyte count with left shift, non-specific elevation of serum amylase, fever only when infection is present [17]-[20]. 


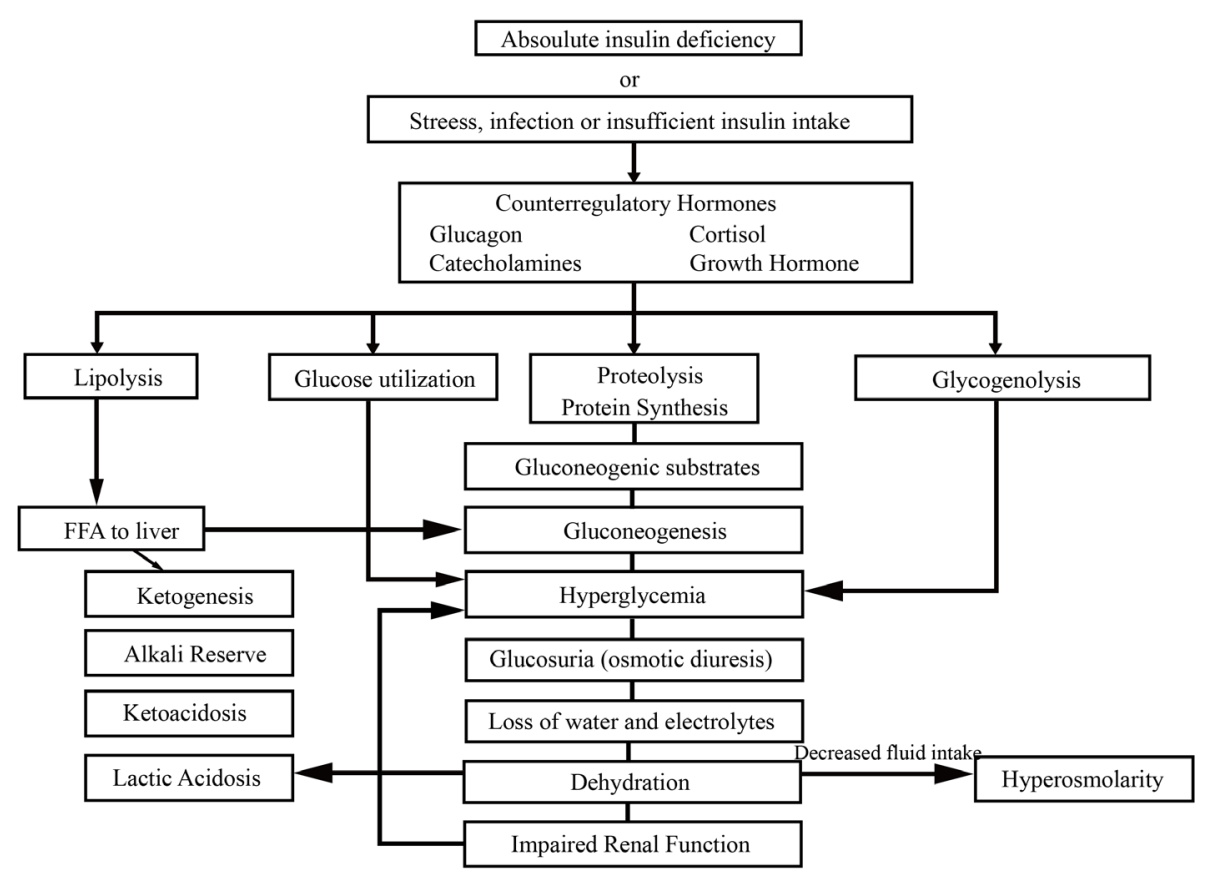

Figure 1. Pathogenesis of DKA as reported by J. Wolfsdorf et al. in 2006 [16]. Insulin deficiency due to several possible causes induces a reduction in glucose utilization and stimulates different metabolic processes to increase glucose production, as glycogenolysis, gluconeogenesis and lypolisis. Hyperglycemia per se, stimulates osmotic diuresis, electrolyte loss, dehydration, decreased glomerular filtration and hyperosmolarity.

The biochemical criteria for the diagnosis of DKA are: hyperglycemia (blood glucose $>11 \mathrm{mmol} / \mathrm{L}[\approx 200$ $\mathrm{mg} / \mathrm{dL}]$ ), venous $\mathrm{pH}<7.3$ or bicarbonate $<15 \mathrm{mmol} / \mathrm{L}$, ketonemia and ketonuria. The severity of DKA is categorized by the degree of acidosis and subdivided into three main categories [21]:

- Mild: venous $\mathrm{pH}<7.3$ or bicarbonate $<15 \mathrm{mmol} / \mathrm{L}$;

- Moderate: $\mathrm{pH}<7.2$, bicarbonate $<10 \mathrm{mmol} / \mathrm{L}$;

- Severe: $\mathrm{pH}<7.1$, bicarbonate $<5 \mathrm{mmol} / \mathrm{L}$.

DKA could present both at T1DM onset and in children with established diabetes. Management is summarized in Figure 2. DKA presents several pitfalls, due to difficulties in diagnosis and in management. According to the norms of good clinical practice and following the international flow-charts presented below, many questions remain opened. It is important to bear in mind that the successful management of DKA requires meticulous monitoring of the patient's clinical and biochemical response to the treatment. First of all the patient with DKA has to be considered as dehydrated, remembering that Sodium blood levels are no indicative of the severity of the loss of fluids. The Corrected $\mathrm{Na}$ is calculated by: Measured $\mathrm{Na}+2$ ([plasma glucose $\mathrm{mg} / \mathrm{dl}-100] / 100$ ) [22]-[24].

This is the real value of $\mathrm{Na}$ that has to be considered in clinical practice. The calculation of effective osmolality $(\mathrm{mOsm} / \mathrm{kg})$ is: $2 \times(\mathrm{Na}+\mathrm{K})+($ glucose $\mathrm{mg} / \mathrm{d} / \mathrm{l}$ ). Important adjustments have also to be considered [25] [26] to establish the right amount of fluids and electrolyte replacement.

Insulin infusion has to be initiated after at least one or two hours from the fluids onset at the dose of 0.1 $\mathrm{IU} / \mathrm{Kg} /$ hour and has to be maintained at least until the resolution of DKA [27] [28].

Another important pitfall is the use of Potassium in fluids replacement. As well known, acidosis moves $\mathrm{K}+$ from intra- to extra-cellular fluids and the child can be apparently normokaliemic, but it is important to bear in mind that in DKA a mean loss of $\mathrm{K}+$ is estimated in $4 \mathrm{mEq} / \mathrm{kgbw}$.

However, depending on the biochemical data of the patients, a following scheme is suggested:

- Hypokalemic: start potassium replacement at the time of initial volume expansion and before starting insulin therapy.

- Normokalemic: start replacing potassium after initial volume expansion and concurrent with starting insulin therapy. 
Immediate assessment

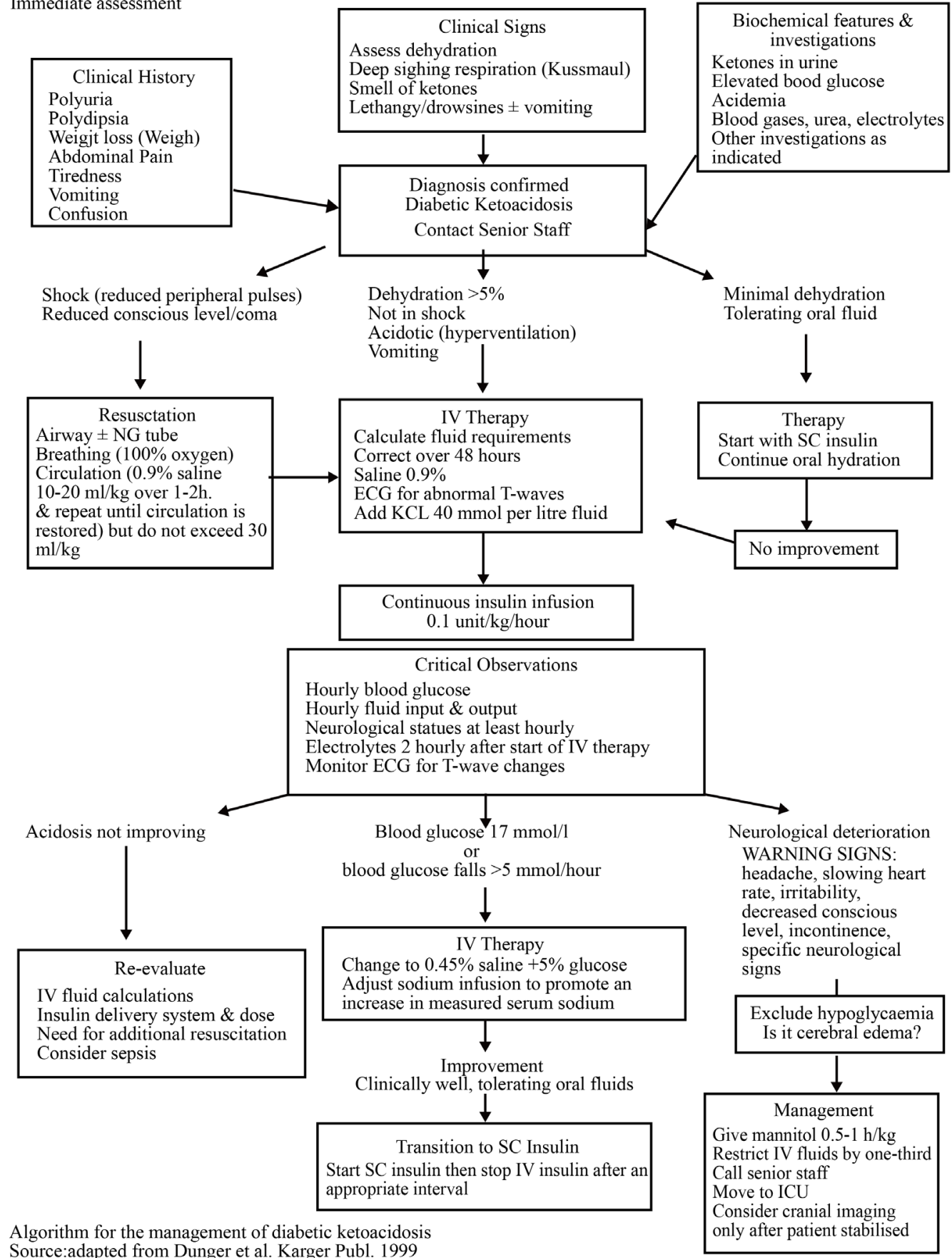

Source:adapted from Dunger et al. Karger Publ. 1999

NG, nasogastric; SC, subcutaneous.

Figure 2. [17]: Flow chart of DKA treatment, according to The International Society of Pediatric and Adolescent Diabetes (ISPAD) guidelines. Management of DKA could be difficult because of the severity of acidosis: it is very important to proceed gradually starting with the clinical evaluation (to confirm the diagnosis and determine its cause), the measurement of weight and height (to determine the surface area), the assessment of dehydration and the consciousness level. In patients at high risk for shock we have to ensure advanced life supports as security of airways, vital signs monitoring, empty the stomach by continuous nasogastric suction, catheterization of bladder, oxygen, two peripheral intravenous catether. Blood and urine tests have to be rapidly performed, evaluating: glucose, renal function, Hemoglobin and full blood count, Venous $\mathrm{pH}$, $\mathrm{pCO}_{2}$, Electrolytes, Osmolality, Calcium, Phosphorus, Magnesium, HbA1c, ketones in urine, blood b-hydroxybutyrate concentration (if available). It is also important to collect specimens for cultures (blood, urine, throat), if there is evidence of infection (fever) and to perform the electrocardiogram (ECG), for baseline evaluation of potassium status. 
- Hyperkalemic: defer potassium replacement therapy until urine output is documented.

The starting potassium concentration in the fluids should be $40 \mathrm{mmol} / \mathrm{L}$. Subsequent potassium replacement therapy should be based on serum potassium measurements. The maximum recommended rate of intravenous potassium replacement is usually $0.5 \mathrm{mmol} / \mathrm{kg} / \mathrm{hr}$, half of which potassium phosphate and the rest potassium chloride [17] [29] [30].

It is also important to underline that bicarbonate infusion is generally not needed in DKA: according to literature, severe acidosis is reversible by fluids and insulin replacement. Bicarbonate infusion has to be considered only in cases of severe academia (arterial $\mathrm{pH}<7.0$ ), decreased cardiac contractility and peripheral vasodilatation and Life-threatening hyperkalemia with dosage of $1-2 \mathrm{mmol} / \mathrm{kg}$ over 60 minutes [31]-[33].

Last, but not least, one of the most insidious complications of DKA replacement therapy is the development of Cerebral Edema. The risk is higher in: younger age, longer duration of symptoms, severe acidosis, bicarbonate treatment for correction of acidosis, an attenuated rise in measured serum sodium concentrations during therapy, greater volumes of fluid given in the first 4 hours, administration of insulin in the first hour of fluid treatment. Warning signs and symptoms to be evaluated are: development of headache and slowing of heart rate, changing in neurological status and/or specific neurological signs (e.g. cranial nerve palsies), rising of blood pressure and decreased of oxygen saturation. Treatment recommended is Mannitol $0.5-1 \mathrm{gr} / \mathrm{Kg}$ over 20 minutes [17] [34] [35].

The management of DKA requires clinical experience and careful monitoring of clinical conditions of the child; it is mandatory to avoid any rapid normalization of the biochemical values. A progressive slow recovery of normal values is generally the best strategy.

\section{Insulin Therapy According to Age}

Types of insulin and procedures to manage the disease according to different ages are summarised in Table 1 and Table 2.

Whatever might be the age considered, the main goal of T1DM treatment remain to give the right quantity of insulin to allow a normal growth and to maintain blood glucose levels in the right range to avoid hypoglycaemia and to obtain good glycosylated hemoglobin values.

From a practical point of view, however, the main goal is to allow a satisfactory social life of children and families, bearing in mind that treatment should be adapted to the life habits of each patient and not the other way round [36].

Pitfalls of stable T1DM management could be subdivided into four main categories, according to age:

- Neonatal diabetes: The main goal of the treatment is to avoid hypoglicemia episodes. This is very complex to obtain due to the high number of meals (up to $7-8$ feedings per day), the unpredictable food intake of neonates, the low amount of insulin with each injection, the extreme neonatal sensitivity to insulin, the vulnerability of the central nervous system to hypoglycaemia and the reduced neonatal glycogen stores. Initially phases of the treatment are based on the continuous intravenous administration of rapid-acting insulin at the dosage of $0.02-0.05 \mathrm{U} / \mathrm{kg} /$ hour, to be prolonged as long as possible before starting with subcutaneous administrations [36] [37].

Table 1. Summary of different kind of Insulin and their action profile.

\begin{tabular}{cccc}
\hline Insulin type & Onset of action (h) & Peak of action (h) & Duration of action (h) \\
\hline Rapid acting analogs (aspart, glulisine, lispro) & $0.15-0.35$ & $1-3$ & $3-5$ \\
Regular/soluble (short acting) & $0.5-1$ & $2-4$ & $5-8$ \\
Intermediate acting Semilente (pork) & $1-2$ & $4-10$ & $8-16$ \\
NPH (Neutral Protamine Hagedorn insulin) & $2-4$ & $4-12$ & $12-24$ \\
IZS (insulin zinc suspension) Lente type & $3-4$ & $6-15$ & 24 \\
Basal long-acting analogs: & & None & $20-24$ \\
Glargine \\
Detemir
\end{tabular}


Table 2. T1DM management according to different ages [36] [37].

\begin{tabular}{|c|c|c|c|}
\hline Ages & Insulin request & Insulin type & $\begin{array}{l}\text { Number of subcutaneously } \\
\text { administrationslday }\end{array}$ \\
\hline Neonatelfirst year of age & $\begin{array}{l}0.25-0.5 \mathrm{UI} / \mathrm{dose} \\
\quad(6-8 \text { meals })\end{array}$ & $\begin{array}{l}\text { Intermediate acting insulins } \\
\text { associated or not to regular insulin }\end{array}$ & 1 to 3 injections \\
\hline One to four years of age & $\begin{array}{c}0.5-0.8 \mathrm{UI} / \mathrm{Kg} / \mathrm{die} \\
(40 \% \text { have to be represented } \\
\text { by basal insulinization) }\end{array}$ & $\begin{array}{l}\text { Basal insulinization: } \\
\text { Intermediate acting insulin in } 2 \text { or } 3 \\
\text { administrations or long acting in } \\
\text { one administration (now available } \\
\text { for this age range) } \\
\text { Meals: } \\
\text { Regular insulin } \\
\text { Or } \\
\text { Rapid Acting Analogs }\end{array}$ & At list 3 injections \\
\hline \multirow{3}{*}{ School age } & $0.7-1.0 \mathrm{U} / \mathrm{Kg} / \mathrm{die}$ & $\begin{array}{l}\text { Basal insulinization: } \\
\text { Long acting }\end{array}$ & \\
\hline & $\begin{array}{l}\text { ( } 40 \% \text { have to be represented } \\
\text { by basal insulinization) }\end{array}$ & $\begin{array}{c}\text { Meals: } \\
\text { Regular insulin } \\
\text { Or } \\
\text { Rapid Acting Analogs }\end{array}$ & $3-4$ injections \\
\hline & $\begin{array}{l}\text { During puberty: } \\
1.0-1.8 \mathrm{UI} / \mathrm{Kg} / \mathrm{die}\end{array}$ & $\begin{array}{l}\text { Basal insulinization: } \\
\text { Long acting in one }\end{array}$ & \\
\hline Adolescence & $\begin{array}{c}\text { After the spurt: } \\
0.7-1 \mathrm{UI} / \mathrm{Kg} / \mathrm{die} \\
(40 \% \text { have to be represented } \\
\text { by basal insulinization) }\end{array}$ & $\begin{array}{c}\text { Meals: } \\
\text { Regular insulin } \\
\text { Or } \\
\text { Rapid Acting Analogs }\end{array}$ & 4 injections \\
\hline
\end{tabular}

- One to four years of age (Toddler): In addition to the most part of the pitfalls listed above, the toddler presents the unpredictability of energy consumption due to the movement. These children spend a lot of time with different figures, like grandparents or nurses, who could have difficulties in disease management [36].

- School age: This is the most stable age to manage T1DM due to the schematic daily routine of these patients [36].

- Adolescence: This period is characterized by the physiological increased needing of insulin due to pubertal spurt. Moreover, adolescence is characterized by behavioural problems, which could negatively influence the disease management. Patients usually show "rebellion" due to independence needing that lead to interruption of self-control practices and sometimes even of insulin injections. It is also present a propensity to transgression with possible experiences of smoking, alcohol and drugs and, mainly in girls, eating disorders [37].

\section{Dietary Recommendations: Which Is the Best Choice?}

Diet management for children with diabetes is based on healthy rules suitable for the whole family as appropriate lifestyle changes [38]. Nutrition and insulin regimen have to be adapted to cultural traditions, ethnicity and psychosocial needs. The main goal of the healthy diet is to provide sufficient and appropriate energy intake for optimal growth and development. Total energy intake should be subdivided as follow [39]:

Carbohydrates: $50 \%-55 \%$ with moderate sucrose intake (up to $10 \%$ total energy)

Fats: $30 \%-35 \%$ :

$<10 \%$ saturated fat + trans fatty acids

$<10 \%$ polyunsaturated fat

$>10 \%$ monounsaturated fat (up to $20 \%$ total energy)

n-3 fatty acids (cis configuration): $0.15 \mathrm{~g} /$ day

Proteins: $10 \%-15 \%$ 
Three balanced meals per day with two appropriate healthy snacks could represent the best diet plan to maintain regular weight and glucose levels. Methods like the "Food Pyramid" (describing foods distributed in a pyramid, with the free eatable on the basis and, the more moving to the top, the less are the quantities) could be very useful to select the right food for each meal. Energy intake varies greatly within subjects on a daily basis due to age, growth rate, energy expenditure and environmental factors [37]-[39].

Recently a new method to manage the energy intake has been developed, called "Carbohydrate counting": a serious over-simplification suggesting that glycaemic control is only affected by the amount and type of carbohydrate [40].

In particular, for diabetic patients the most used method is the "Insulin-to-carbohydrate ratios", particularly appropriate for people on Multiple Daily Injections or insulin pump therapy. It involves the calculation of insulin-to-carbohydrate ratios that are individualized for each child according to age, sex, pubertal status, duration of diagnosis, time of day and activity. The ratio leads to adjustment of pre-meal insulin according to the estimated carbohydrates content of the meal. According to literature, the amount of insulin able to metabolize $15 \mathrm{gr}$ of carbohydrates is $0.5-1 \mathrm{UI}$ in adults. A practical procedure is to divide 450 (using regular insulin) or 500 (using rapid acting analog) by the amount of insulin in a day (IU): the result of the ratio is the quantity of carbohydrates metabolized by one IU of insulin [39]-[41].

Even if the method shows a good efficacy in adults with T1DM, its role in children is still controversial due to two main reasons:

1) Post-prandial glycemia is influenced by carbohydrates, proteins and lipids content of the meal. The count considers only carbohydrates and may introduce an excess of calories due to the other main nutrients, or to develop a diet poor in proteins and lipids.

2) Children and families involved in carbohydrate count are often under pressure, due to the difficulty to manage other important numbers in their daily routine.

Using the count in children could be considered another pitfall in management of T1DM [39].

\section{Conclusions}

The management of children with diabetes is a complex task since its diagnosis, and any doctor has to keep in mind that an early diagnosis allows avoiding fatal consequences.

Difficulties are present at any step of growth and they change year by year. New devices and types of insulin have made the management of this condition easier, improving the quality of life, but the real improvement in treatment can derive only by a progressive empowerment of the patient and their family.

\section{References}

[1] American Diabetes Association (2007) Diagnosis and Classification of Diabetes Mellitus. Diabetes Care, 30, S42S47. http://dx.doi.org/10.2337/dc07-S042

[2] Erlich, H., Valdes, A.M., Noble, J., Carlson, J.A., Varney, M., Concannon, P., Mychaleckyj, J.C., Todd, J.A., Bonella, P., Fear, A.L., Lavant, E., Louey, A. and Moonsamy, P. (2008) Type 1 Diabetes Genetics Consortium. HLA DR-DQ Haplotypes and Genotypes and Type 1 Diabetes Risk: Analysis of the Type 1 Diabetes Genetics Consortium Families. Diabetes, 57, 1084-1092. http://dx.doi.org/10.2337/db07-1331

[3] Lambert, A.P., Gillespie, K.M., Thomson, G., Cordell, H.J., Todd, J.A., Gale, E.A. and Bingley, P.J. (2004) Absolute Risk of Childhood-Onset Type 1 Diabetes Defined by Human Leukocyte Antigen Class II Genotype: A Population-Based Study in the United Kingdom. Journal of Clinical Endocrinology and Metabolism, 89, 4037-4043. http://dx.doi.org/10.1210/jc.2003-032084

[4] Sabbah, E., Savola, K., Ebeling, T., Kulmala, P., Vähäsalo, P., Ilonen, J., Salmela, P.I. and Knip, M. (2000) Genetic, Autoimmune, and Clinical Characteristics of Childhood and Adult-Onset Type 1 Diabetes. Diabetes Care, 23, 13261332. http://dx.doi.org/10.2337/diacare.23.9.1326

[5] Verge, C.F., Stenger, D., Bonifacio, E., Colman, P.G., Pilcher, C., Bingley, P.J. and Eisenbarth, G.S. (1998) Combined Use of Autoantibodies (IA-2 Autoantibody, GAD Autoantibody, Insulin Autoantibody, Cytoplasmic Islet Cell Antibodies) in Type 1 Diabetes: Combinatorial Islet Autoantibody Workshop. Diabetes, 47, 1857-1866. http://dx.doi.org/10.2337/diabetes.47.12.1857

[6] Skyler, J.S., Krischer, J.P., Wolfsdorf, J., Cowie, C., Palmer, J.P., Greenbaum, C., Cuthbertson, D., Rafkin-Mervis, L.E., Chase, H.P. and Leschek, E. (2005) Effects of Oral Insulin in Relatives of Patients with Type 1 Diabetes: The Diabetes Prevention Trial-Type 1. Diabetes Care, 28, 1068-1076. http://dx.doi.org/10.2337/diacare.28.5.1068 
[7] Verge, C.F., Gianani, R., Kawasaki, E., Yu, L., Pietropaolo, M., Jackson, R.A., Chase, H.P. and Eisenbarth, G.S. (1996) Prediction of Type 1 Diabetes in First-Degree Relatives Using a Combination of Insulin, GAD, and ICA512bdc/IA-2 Autoantibodies. Diabetes, 45, 926-933. http://dx.doi.org/10.2337/diab.45.7.926

[8] Dotta, F., Censini, S., van Halteren, A.G., Marselli, L., Masini, M., Dionisi, S., Mosca, F., Boggi, U., Muda, A.O., Del Prato, S., Elliott, J.F., Covacci, A., Rappuoli, R., Roep, B.O. and Marchetti, P. (2007) Coxsackie B4 Virus Infection of Beta Cells and Natural Killer Cell Insulitis in Recent-Onset Type 1 Diabetic Patients. Proceedings of the National Academy of Sciences of the United States of America, 104, 5115-5120. http://dx.doi.org/10.1073/pnas.0700442104

[9] Richardson, S.J., Willcox, A., Bone, A.J., Foulis, A.K. and Morgan, N.G. (2009) The Prevalence of Enteroviral Capsid Protein Vp1 Immunostaining in Pancreatic Islets in Human Type 1 Diabetes. Diabetologia, 52, 1143-1151. http://dx.doi.org/10.1007/s00125-009-1276-0

[10] Majaliwa, E.S., Elusiyan, B.E., Adesiyun, O.O., Laigong, P., Adeniran, A.K., Kandi, C.M., Yarhere, I., Limbe, S.M. and Iughetti, L. (2008) Type 1 Diabetes Mellitus in the African Population: Epidemiology and Management Challenges. Acta Biomedica, 79, 255-259.

[11] EURODIAB ACE Study Group (2000) Variation and Trends in Incidence of Childhood Diabetes in Europe. The Lancet, 355, 873-876. http://dx.doi.org/10.1016/S0140-6736(99)07125-1

[12] Bruno, G., Maule, M., Merletti, F., Novelli, G., Falorni, A., Iannilli, A., Iughetti, L., Altobelli, E., d'Annunzio, G., Piffer, S., Pozzilli, P., Iafusco, D., Songini, M., Roncarolo, F., Toni, S., Carle, F. and Cherubini,V., RIDI Study Group (2010) Age-Period-Cohort Analysis of 1990-2003 Incidence Time Trends of Childhood Diabetes in Italy: The Ridi Study. Diabetes, 59, 2281-2287. http://dx.doi.org/10.2337/db10-0151

[13] International Society for Paediatric and Adolescent Diabetes (2009) Clinical Practice Consensus Guidelines 2009 Compendium. Phases of Diabetes in Children and Adolescents. Pediatric Diabetes, 10, 13-16.

[14] Bober, E., Dundar, B. and Buyukgebiz, A. (2001) Partial Remission Phase and Metabolic Control in Type 1 Diabetes Mellitus in Children and Adolescents. Journal of Pediatric Endocrinology and Metabolism, 14, 435-441. http://dx.doi.org/10.1515/jpem.2001.14.4.435

[15] The Diabetes Control and Complications Trial Research Group (1998) Effect of Intensive Therapy on Residual BetaCell Function in Patients with Type Diabetes in the Diabetes Control and Complications Trial. A Randomized, Controlled Trial. Annals of Internal Medicine, 128, 517-523. http://dx.doi.org/10.7326/0003-4819-128-7-199804010-00001

[16] Wolfsdorf, J., Glaser, N. and Sperling, M.A. (2006) Diabetic Ketoacidosis in Infants, Children, and Adolescents: A Consensus Statement from the American Diabetes Association. Diabetes Care, 29, 1150-1159. http://dx.doi.org/10.2337/dc06-9909

[17] Wolfsdorf, J., Craig, M.E., Daneman, D., Dunger, D., Edge, J., Lee, W., Rosenbloom, A., Sperling, M. and Hanas, R. (2009) Diabetic Ketoacidosis in Children and Adolescents with Diabetes. Pediatric Diabetes, 10, 118-133.

[18] Foster, D.W. and McGarry, J.D. (1983) The Metabolic Derangements and Treatment of Diabetic Ketoacidosis. The New England Journal of Medicine, 309, 159-169. http://dx.doi.org/10.1056/NEJM198307213090307

[19] Kitabchi, A.E., Umpierrez, G.E., Murphy, M.B. and Kreisberg, R.A. (2006) Hyperglycemic Crises in Adult Patients with Diabetes: A Consensus Statement from the American Diabetes Association. Diabetes Care, 29, 2739-2748. http://dx.doi.org/10.2337/dc06-9916

[20] Hanas, R., Lindgren, F. and Lindblad, B. (2009) A 2-yr National Population Study of Pediatric Ketoacidosis in Sweden: Predisposing Conditions and Insulin Pump Use. Pediatric Diabetes, 10, 33-37. http://dx.doi.org/10.1111/j.1399-5448.2008.00441.x

[21] Chase, H.P., Garg, S.K. and Jelley, D.H. (1990) Diabetic Ketoacidosis in Children and the Role of Outpatient Management. Pediatrics in Review, 11, 297-304. http://dx.doi.org/10.1542/pir.11-10-297

[22] Linares, M.Y., Schunk, J.E. and Lindsay, R. (1996) Laboratory Presentation in Diabetic Ketoacidosis and Duration of Therapy. Pediatric Emergency Care, 12, 347-351. http://dx.doi.org/10.1097/00006565-199610000-00006

[23] Koves, I.H., Neutze, J., Donath, S., Lee, W., Werther, G.A., Barnett, P. and Cameron, F.J. (2004) The Accuracy of Clinical Assessment of Dehydration during Diabetic Ketoacidosis in Childhood. Diabetes Care, 27, 2485-2487. http://dx.doi.org/10.2337/diacare.27.10.2485

[24] Harris, G.D. and Fiordalisi, I. (1994) Physiologic Management of Diabetic Ketoacidemia. A 5-Year Prospective Pediatric Experience in 231 Episodes. Archives of Pediatrics and Adolescent Medicine, 148, 1046-1052. http://dx.doi.org/10.1001/archpedi.1994.02170100044009

[25] Katz, M.A. (1973) Hyperglycemia-Induced Hyponatremia-Calculation of Expected Serum Sodium Depression. The New England Journal of Medicine, 289, 843-844. http://dx.doi.org/10.1056/NEJM197310182891607

[26] Hillier, T.A., Abbott, R.D. and Barrett, E.J. (1999) Hyponatremia: Evaluating the Correction Factor for Hyperglycemia. The American Journal of Medicine, 106, 399-403. http://dx.doi.org/10.1016/S0002-9343(99)00055-8 
[27] Kitabchi, A.E. (1989) Low-Dose Insulin Therapy in Diabetic Ketoacidosis: Fact or Fiction? Diabetes/Metabolism Research and Reviews, 5, 337-363. http://dx.doi.org/10.1002/dmr.5610050403

[28] Edge, J.A., Jakes, R.W., Roy, Y., Hawkins, M., Winter, D., Ford-Adams, M.E., Murphy, N.P., Bergomi, A., Widmer, B. and Dunger, D.B. (2006) The UK Case-Control Study of Cerebral Oedema Complicating Diabetic Ketoacidosis in Children. Diabetologia, 49, 2002-2009. http://dx.doi.org/10.1007/s00125-006-0363-8

[29] Adrogue, H.J., Lederer, E.D., Suki, W.N. and Eknoyan, G. (1986) Determinants of Plasma Potassium Levels in Diabetic Ketoacidosis. Medicine (Baltimore), 65, 163-172. http://dx.doi.org/10.1097/00005792-198605000-00004

[30] Defronzo, R.A., Felig, P., Ferrannini, E. and Wahren, J. (1980) Effect of Graded Doses of Insulin on Splanchnic and Peripheral Potassium Metabolism in Man. American Journal of Physiology, 238, E421-E427.

[31] Assal, J.P., Aoki, T.T., Manzano, F.M. and Kozak, G.P. (1974) Metabolic Effects of Sodium Bicarbonate Inmanagement of Diabetic Ketoacidosis. Diabetes, 23, 405-411. http://dx.doi.org/10.2337/diab.23.5.405

[32] Soler, N.G., Bennett, M.A., Dixon, K., Fitzgerald, M.G. and Malinis, J.M. (1972) Potassium Balance during Treatment of Diabetic Ketoacidosis with Special Reference to the Use of Bicarbonate. The Lancet, 30, 665-667. http://dx.doi.org/10.1016/S0140-6736(72)92083-1

[33] Narins, R.G. and Cohen, J.J. (1987) Bicarbonate Therapy for Organic Acidosis: The Case for Its Continued Use. Annals of Internal Medicine, 106, 615-618. http://dx.doi.org/10.7326/0003-4819-106-4-615

[34] Edge, J.A. (2000) Cerebral Oedema during Treatment of Diabetic Ketoacidosis: Are We Any Nearer Finding a Cause? Diabetes/Metabolism Research and Reviews, 16, 316-324. http://dx.doi.org/10.1002/1520-7560(2000)9999:9999<::AID-DMRR143>3.0.CO;2-R

[35] Muir, A.B., Quisling, R.G., Yang, M.C. and Rosenbloom, A.L. (2004) Cerebral Edema in Childhood Diabetic Ketoacidosis: Natural History, Radiographic Findings, and Early Identification. Diabetes Care, 27, 1541-1546. http://dx.doi.org/10.2337/diacare.27.7.1541

[36] Bangstad, H.J., Danne, T., Deeb, L., Jarosz-Chobot, P., Urakami, T. and Hanas, R. (2009) Insulin Treatment in Children and Adolescents with Diabetes. Pediatric Diabetes, 10, 82-99.

[37] National Collaborating Centre for Women's and Children's Health (2004) Type 1 Diabetes: Diagnosis and Management of Type 1 Diabetes in Children and Young People. RCOG Press, London.

[38] American Diabetes Association (2003) Nutrition Principles and Recommendations in Diabetes (Position Statement). Diabetes Care, 27, S36-S46.

[39] Smart, C., Aslander-van, V.E. and Waldron, S. (2009) Nutritional Management in Children and Adolescents with Diabetes. Pediatric Diabetes, 10, 100-117.

[40] Gillespie, S.J., Kulkarni, K.D. and Daly, A.E. (1998) Using Carbohydrate Counting in Diabetes Clinical Practice. Journal of the American Dietetic Association, 98, 897-905. http://dx.doi.org/10.1016/S0002-8223(98)00206-5

[41] Gilbertson, H.R., Brand-Miller, J.C., Thorburn, A.W., Evans, S., Chondros, P. and Werther, G.A. (2001) The Effect of Flexible Low Glycemic Index Dietary Advice versus Measured Carbohydrate Exchange Diets on Glycemic Control in Children with Type 1 Diabetes. Diabetes Care, 24, 1137-1143. http://dx.doi.org/10.2337/diacare.24.7.1137 